\title{
Wanneer flankpijn op de zenuwen werkt: een nieuwe diagnose?
}

\author{
Olaf. P. J. Vrooman · Michael R. van Balken
}

Published online: 28 September 2020

(c) The Author(s) 2020

\begin{abstract}
Samenvatting Wanneer patiënten worden verwezen met flankpijn, zet de uroloog meestal laboratoriumen beeldvormend onderzoek in om pathologie aan de nieren en urinewegen aan te tonen of uit te sluiten. Bij een subgroep van patiënten kan geen afwijking worden aangetoond, wat in sommige gevallen leidt tot overmatige diagnostiek. Veelal is er weinig aandacht geweest voor een op de pijn gerichte anamnese en lichamelijk onderzoek. Aan de hand van twee ziektegeschiedenissen en literatuur willen we een 'nieuwe' diagnose van flankpijn onder de aandacht brengen.
\end{abstract}

Trefwoorden urolithiasis - functionele urologie . ACNES · LACNES $\cdot$ POCNES

\section{When flankpain is getting on your nerves}

Abstract When patients are referred with flank pain, the urologist usually uses laboratory and imaging studies to rule out kidney and urinary tract pathology. A diagnosis cannot be found in some of these patients; this may lead to extra diagnostics. In many cases, little attention has been paid to pain-related anamnesis and physical examination. We want to draw attention to a 'new' diagnosis of flank pain based on two cases and literature.

Keywords urolithiasis · functional urology · ACNES · LACNES · POCNES

\section{Introductie}

Flankpijn is pijn tussen de ribbenboog en de bekkenkam. Bij acute flankpijn wordt in de meeste geval-

drs. O. P. J. Vrooman $(\bowtie) \cdot d r$. M. R. van Balken afdeling Urologie, Rijnstate, Arnhem, Nederland ovrooman@rijnstate.nl len gedacht aan een urologische oorzaak. Wanneer pijnklachten echter een minder acuut karakter hebben en beeldvormend onderzoek en bloed- en urinetests geen afwijkingen laten zien, is het stellen van een diagnose vaak niet goed mogelijk. Aan de hand van ziektegeschiedenissen illustreren we dat een subgroep van patiënten met chronische flankpijn op basis van een goede anamnese en lichamelijk onderzoek toch kan worden geholpen.

\section{Casus 1}

Een 28-jarige vrouw presenteert zich op de polikliniek Urologie met pijnklachten in de rechterflank, die enkele weken bestaan. De pijn is continu aanwezig, waarbij ze geen goede houding kan vinden. Haar voorgeschiedenis vermeldt twee episoden met recidiverende urineweginfecties, die inmiddels twee jaar afwezig zijn. Een eerdere door de huisarts aangevraagde echo toonde een milde dilatatie van de rechternier, maar deze nam af na mictie.

Bij de intake werd geen lichamelijk onderzoek gedaan. Wel werden urine- en bloedonderzoek uitgevoerd, waarop geen afwijkingen zichtbaar waren. De CT-IVP was normaal en ook op het renogram waren geen afwijkingen te zien. Pas na dit aanvullende onderzoek werd echt goed lichamelijk onderzoek uitgevoerd naar de oorsprong van de pijn. Hierbij werd lateraal in de midaxillaire lijn, net onder de ribbenboog, een uiterst gelokaliseerde pijnlijke plek gevonden: het punctum maximum van de pijn. Daarop werd prodiagnosi onder het niveau van de spierfascie een injectie geplaatst met $10 \mathrm{ml}$ (1\%) lidocaïne. Hiermee daalde de numerieke pijnscore (op de Numeric Rating Scale; NRS) van 9 naar 3, een niveau dat aan bleef houden tot twee uur na de injectie. Na nog enkele herhaalde injecties met de combinatie lidocaïne/triam was de 
pijn uiteindelijk zodanig beheersbaar dat patiënte uit verdere controle kon worden ontslagen.

\section{Casus 2}

Een 38-jarige vrouw wordt verwezen naar de polikliniek Urologie met sinds twee jaar bestaande pijn in de rechterflank. De pijn is ontstaan na een sectio caesarea van een tweeling, na een eerdere sectio en wordt met name gevoeld in rugligging bij liggen op de rechterzij. Het karakter van de pijn is zeurend en soms stekend.

Ten tijde van de intake werd geen lichamelijk onderzoek gedaan, maar meteen aanvullend onderzoek ingezet. Bloed- en urineonderzoek waren niet afwijkend. In het verslag van de echo nieren werd gedacht aan een hypermobiele nier en hierop volgde een CTIVP en een renogram in staande en liggende houding, maar er werd geen afvloedstoornis geobjectiveerd. Uit het daarop volgende lichamelijk onderzoek bleek dat er een pijnpunt was dorsaal, enkele centimeters rechts van processus spinosus, met pijn die uitstraalde naar de buik. De pijn werd op dat moment als drukkend en brandend ervaren. Op het punctum maximum van de pijn werd $10 \mathrm{ml}$ (1\%) lidocaïne geïnjecteerd onder het niveau van de spierfascie, waarop de pijn afnam tot NRS-score 8, en zelfs kortdurend naar score 0, maar na twee dagen scoorde patiënte weer 6 op de NRS. Daarop volgde een tweede injectie, waarna de pijn dermate was afgenomen dat patiënte weer sportieve activiteiten kon ontplooien en uiteindelijk uit verdere controle kon worden ontslagen.

\section{Meer casuïstiek}

In ons centrum identificeerden we tussen 2015 en 2017 retrospectief in totaal 12 patiënten (11 vrouwen en 1 man, tussen de 28 en 74 jaar (mediaan 49) met gelokaliseerde flankpijn). Aanvullend onderzoek bracht bij geen van hen urologische pathologie aan het licht.

Al deze patiënten kregen uiteindelijk een injectie (onder de spierfascie) met $10 \mathrm{ml}$ (1\%) lidocaïne op het punt waar de maximale pijn werd gevoeld, waardoor bij alle patiënten ten minste tijdelijke verlichting van pijn werd bereikt. Van acht patiënten was de NRSscore voor en na de injectie beschikbaar. De gemiddelde NRS-score vóór lidocaïne-injectie was 7,5 en de gemiddelde NRS-score na lidocaïne-injectie was 1,8. Bij 5 van de 12 patiënten trad minder dan twee uur pijnverlichting op. Bij 7 van de 12 patiënten had het injecteren van lidocaïne een langdurig effect (in sommige gevallen na herhaalde injecties).

\section{Symptomatologie}

Beide uitgebreid beschreven patiënten hebben een aantal zaken gemeen. De pijn was niet acuut ontstaan, was vrijwel continu aanwezig en bestond langere tijd voordat de patiënt zich meldde op de poli- kliniek. Hoewel in beide gevallen de patiënten waren verwezen voor flankpijn bleek de daadwerkelijke oorsprong van de pijn zich niet in de flank te bevinden. Bij beide patiënten is er veel aanvullend onderzoek verricht waarmee de diagnose niet kon worden gesteld. Bij het, in tweede instantie uitgevoerde, lichamelijk onderzoek werd duidelijk dat er geen sprake was van een viscerale pijn die juist diffuus gevoeld wordt, maar van een zeer gelokaliseerde pijn die bij lichamelijk onderzoek geprovoceerd kon worden.

De klachten waarmee beide patiënten zich presenteerden hadden een grote analogie met symptomen van het anterior cutaneous nerve entrapment syndrome (ACNES) [1]. Dit pijnsyndroom van de buikwand wordt waarschijnlijk veroorzaakt door beklemming van de anterieure cutane takken van de thoracoabdominale intercostale zenuwen die gevoeld worden op een specifiek punt aan de ventrale zijde van de buik. Net als bij ACNES kon een diagnose worden gesteld door lokaal lidocaïne te injecteren in een triggerpoint [2]. Op basis van de anatomie valt te beredeneren dat deze pijnklachten mogelijk een variant zijn van ACNES.

\section{Anatomie thoracoabdominale intercostale zenuwen}

De buikwand en de flankregio worden sensorisch geïnnerveerd door zes paar thoracoabdominale intercostale zenuwen (T7-T12) [3, 4]. Deze zenuwen vertakken gewoonlijk op drie plekken (fig. 1):

- aan de rugzijde (posterieur);

- in de flank (lateraal);

- in de voorste buikwand (anterieur) waar de zenuw de musculus (m.) rectus abdominis binnentreedt.

Deze anatomische configuratie leidt tot twee varianten van ACNES, namelijk het lateral cutaneous nerve entrapment syndrome (LACNES) en het posterior cutaneous nerve entrapment syndrome (POCNES).

\section{LACNES}

LACNES is een pijnbeeld waarbij sprake is van neuropathische pijn die lijkt op de pijn bij ACNES, maar dan lateraal in de flank. Kenmerkend is de gelokaliseerde pijn die, in tegenstelling tot meer diffuse viscerale pijn, met een vingertop is aan te wijzen (triggerpoint).

In een retrospectieve studie van Maatman et al. werden 30 patiënten geïncludeerd die waren gediagnosticeerd met LACNES in de periode tussen 2007 en 2016 [5]. In deze studie stond bij de diagnostiek het lichamelijk onderzoek centraal, waarbij de volgende tests werden uitgevoerd: 1) de patiënt wordt gevraagd aan te wijzen waar de pijn zich voornamelijk bevindt (triggerpoint), 2) een wattenstaaf en een in alcohol gedrenkt gaas worden op de huid gebruikt om somatosensore verschillen in de huid vast te kunnen stellen ter hoogte van het triggerpoint, 3) een kneep 
Figuur 1 Het verloop en de distributie van een intercostale zenuw op abdominaal niveau. Tekening: Nikola Kolundzic

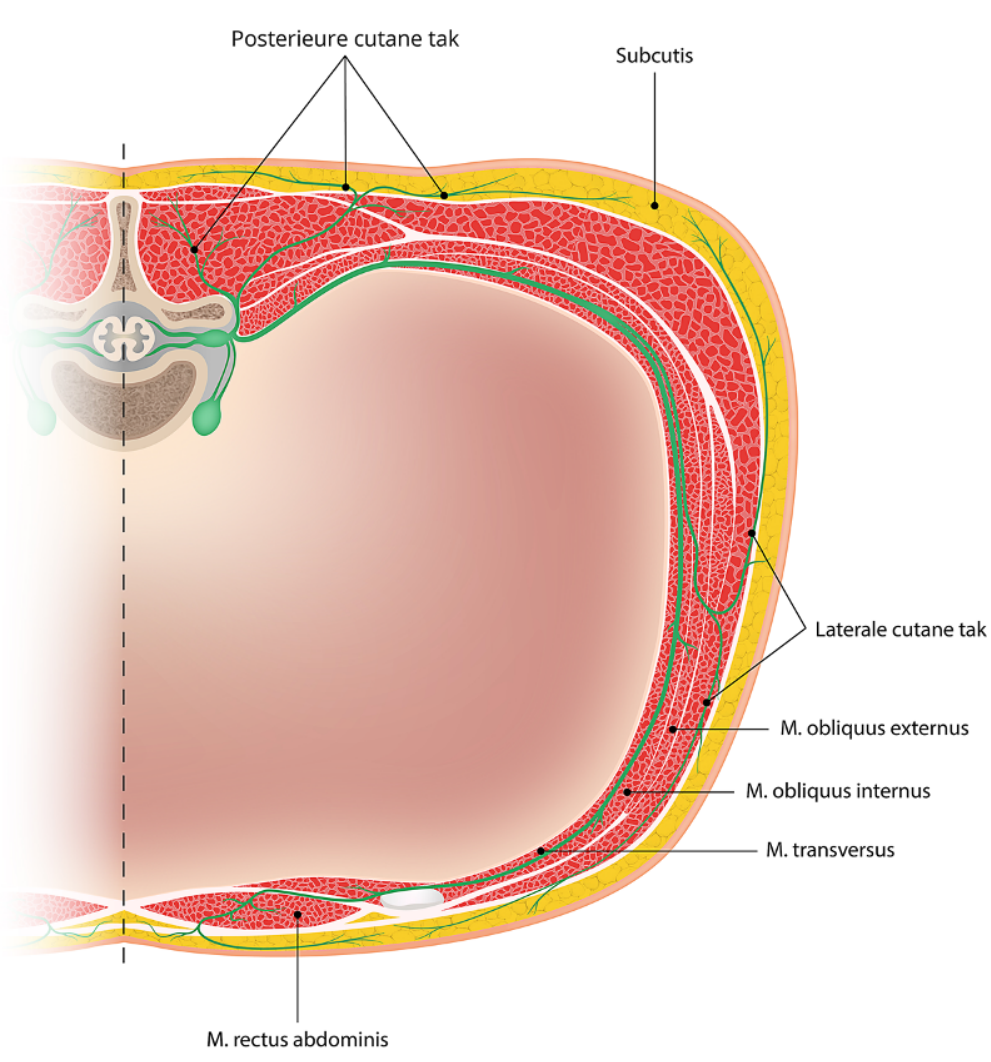

plaatst met lidocaïne, waaraan $40 \mathrm{mg}$ methylprednison was toegevoegd. Definitieve follow-up werd middels een telefonisch interview uitgevoerd, waarin gevraagd werd naar de tevredenheid.

Bij 25 (83\%) van de 30 geïncludeerde patiënten (21 vrouwen) trad pijnreductie op van $>50 \%$ na de initiële diagnostische injectie. Vijf patiënten (17\%) waren na een enkele injectie langdurig pijnvrij (mediaan 60 maanden; range 2-103). Twee patiënten bereikten langdurige pijnvermindering na $1-3$ herhaalde injecties (respectievelijk 36 en 55 maanden). Geconcludeerd werd dat $23 \%$ van deze patiënten met enkel injectietherapie kon worden geholpen. Negen patiënten gaven aan na de injectie kortdurend verbetering te bemerken en opteerden voor een regelmatige injectie in het triggerpoint. Met deze behandeling waren de pijnscores ook op de langere termijn bevredigend. De overall tevredenheid van de injectietherapie kwam daarmee op $53 \%$ (16/30).

\section{POCNES}

POCNES is een pijnbeeld waarbij de neuropathische pijn lijkt op de pijn zoals deze wordt ervaren bij ACNES en LACNES, maar bij POCNES wordt de pijn veroorzaakt door een beklemde cutane tak van de posterieure rami van de thoracale spinale zenuw, doorgaans T11-12 [6]. Ook deze pijn wordt door veel patiënten niet centraal in de rug gevoeld, maar enkele centimeters lateraal van de processus spinosus, waardoor zij de pijn aangeven als flankpijn. In 2017 verscheen het eerste, wederom Nederlandse, case re- 
port waarbij deze pijn als neuropathische pijn werd geduid [7].

\section{Caseserie}

In 2019 publiceerden Maatman et al. een prospectieve studie over 14 patiënten met POCNES [5].

\section{Analyse}

De initiële analyse van deze patiënten startte met een uitgebreide anamnese, waarin aandacht was voor bewegingen die de pijn provoceerden en de eerder toegepaste therapie. Daarnaast werd een gevalideerde vragenlijst gebruikt, de Doleur Neuropathique (DN4) [8]. Met deze vragenlijst is het mogelijk onderscheid te maken tussen neuropathische en nociceptieve pijn. In deze studie werd de 7-items DN4 afgenomen. Bij een afkappunt van 4 van de 7 vragen is de sensitiviteit $74 \%$ en de specificiteit $79 \%$ [9]. In deze studie werd 3 of meer aangehouden als aanwijzing voor neuropathische pijn. De verdere analyse bestond uit hetzelfde uitgebreide lichamelijk onderzoek als bij LACNES. Er werd wel een vijfde criterium gebruikt, namelijk: 'normale resultaten van laboratoriumonderzoek en beeldvorming'. In deze studie werden patiënten geïncludeerd wanneer ze voldeden aan vier van deze vijf criteria.

\section{Interventie}

Bij alle deelnemers werd ter plaatse van het triggerpoint een injectie met $2-5 \mathrm{ml} 1 \%$ lidocaïne geinjecteerd net onder de thoracolumbale fascie van de musculus erector spinae met een $21 \mathrm{G} 40 \mathrm{~mm}$ naald. Deze hoeveelheid werd gebaseerd op gewicht en/of de subcutane dikte rond het triggerpoint. De pijnscores (NRS) werden voor injectie en 10-15 minuten na injectie uitgevraagd. Bij een pijnreductie van $>50 \%$ werd de diagnose POCNES gesteld. Als de pijnklachten terugkwamen, werd opnieuw een injectie geplaatst met $2-5 \mathrm{ml}$ lidocaïne waaraan $40 \mathrm{mg}$ methylprednison was toegevoegd. Toevoegen van een corticosteroïd is bij ACNES overigens niet zinvol gebleken: die toevoeging bleek in een recente studie naar de effectiviteit daarvan niet te leiden tot een verschil met het injecteren van lidocaïne alleen [10].

\section{Resultaten}

Bij 11 (85\%) van de 14 geïncludeerde patiënten (12 vrouwen) bij wie de diagnose POCNES werd gesteld, nam de pijn na injectie af met $>50 \%$ (NRSscore van mediaan 8 (IQR: 7,0-8,0) naar mediaan 3,0 (IQR $1,5-3,5) ; p<0,001$ ). Eén patiënt was tevreden met herhaalde injecties, twee patiënten weigerden chirurgie voor een definitieve oplossing. Uiteindelijk werd bij 11 patiënten een neurectomie uitgevoerd, die succesvol was bij 7 (64\%) patiënten. Op de lange termijn (mediaan 29 maanden follow-up, range 5-48) werd bij $57 \%$ van de deelnemers een aanhoudend positief effect bereikt.

\section{Algoritme van diagnose en behandeling}

Op basis van de huidige kennis van AGNES en POCNES doen we de volgende aanbeveling voor de diagnose en behandeling van patiënten met onbegrepen flankpijn (kader).

\section{Discussie}

LACNES en POCNES zijn nog maar zelden onderzocht en de literatuur erover is schaars. ACNES is inmiddels wel beter omschreven. De diagnostische criteria en behandeling zijn dan ook afgeleiden van de ervaring die is opgedaan bij ACNES [11].

Zowel de retrospectieve als de prospectieve studie van Maatman et al. [3, 5] toont aan dat flank- en rugpijn niet altijd hun oorsprong vinden in de urologische organen of het bewegingsapparaat, terwijl veel van deze patiënten bij aanhoudende pijn zullen worden verwezen naar een uroloog. Het is voor zowel patiënten als verwijzende artsen vaak lastig om precies de pijnlocatie te duiden, waardoor de 'flank' een

\section{Algoritme van diagnose en behandeling}

1. Anamnestische criteria:

a.langdurige pijn;

b.de pijn bevindt zich op één specifieke plek in de flank en is met één vinger aan te wijzen;

c. de pijn neemt toe bij een bepaalde houding;

d.de pijn is dof zeurend en soms stekend;

e. kleding kan irritatie geven.

2. Lichamelijk onderzoek:

a.de pijn is op te wekken op één specifieke plek in de flank (triggerpoint);

b.de sensibiliteit van de huid rond het triggerpoint is verstoord;

c. een pinch test is pijnlijker rond het triggerpoint.

3. Aanvullend onderzoek bij twijfel aan de diagnose:

a.laboratoriumonderzoek;

b. beeldvorming.

4. Diagnostische injectie met lidocaïne:

a. ter hoogte van triggerpoint $2,5-5 \mathrm{ml}$ lidocaïne $1 \%$.

5. Eventueel herhaalde injecties afhankelijk van de werkzaamheid:

a. opnieuw lidocaïne $1 \%$ (corticosteroïden lijken niet aanvullend te werken)

6. Pulsed radiofrequency (PRF)

7. Neurectomie van cutane takken van de intercostale zenuwen ter hoogte van het triggerpoint. 
uitgebreidere regio blijkt te omvatten dan urologen doorgaans definiëren. De differentiaaldiagnose van chronische flankpijn is dan ook uitgebreider dan de differentiaaldiagnose die is gerelateerd aan pathologie van de nieren en urinewegen. Uit onze eigen ervaring met deze groep patiënten, die vaak lang zoeken naar een diagnose en oplossing van hun klachten, blijkt dat er door gebruik te maken van anamnese en lichamelijk onderzoek veel bespaard kan worden op de kosten van overbodige diagnostiek, net als bij de diagnosestelling van ACNES [11]. Veel belangrijker wellicht is dat bij deze patiënten, die vaak lang in de medische molen zitten met 'onbegrepen' pijnklachten, een diagnose kan worden gesteld. Een diagnose waarbij in het merendeel van de gevallen op simpele wijze met behulp van een lidocaïne-injectie een behoorlijke en langdurige pijnverlichting kan worden bereikt. In de twee Nederlandse studies wordt de diagnose gesteld bij een pijnreductie van ten minste $50 \%$. Dit is een strenge norm, want in de literatuur over chronische pijn wordt gesproken van een klinisch-relevante pijnreductie bij een pijnafname tussen de $30-50 \%[12,13]$. In de praktijk is een minder grote pijnreductie dan de genoemde $50 \%$ dus ook vaak al voldoende om de diagnose te stellen en de behandeling te continueren. Wanneer de behandeling met lidocaïne niet voldoende (lang) effect heeft, kan als tweede stap pulsed radiofrequency (PRF) worden verricht via een pijnspecialist. Bij ACNES leidde behandeling met PRF tot een pijnreductie bij $38 \%$ van de patiënten tegenover $61 \%$ in de groep die werden behandeld met neurectomie [14]. Wanneer minimaal invasieve behandeling met injecties en PRF falen, kan neurectomie dus worden overwogen. Bij deze ingreep wordt de door de spierfascie perforerende cutane tak van de nervus intercostalis geligeerd en verwijderd.

\section{Conclusie}

In een tijd dat anamnese en lichamelijk onderzoek grotendeels worden vervangen door laboratoriumen/of beeldvormend onderzoek, zien we dat sommige klachten niet tot een diagnose en behandeling leiden. Patiënten met pijn in de flankregio zullen vaak naar de uroloog worden verwezen en het is daarom van belang dat ook de uroloog op de hoogte is van de alternatieve diagnose LACNES en POCNES om onnodig onderzoek en zorgconsumptie te voorkomen. Het door ons opgestelde algoritme voor de diagnose en behandeling van patiënten met onbegrepen flankpijn kan daarbij als hulpmiddel dienen.

Open Access This article is distributed under the terms of the Creative Commons Attribution 4.0 International License (http://creativecommons.org/licenses/by/4.0/), which permits unrestricted use, distribution, and reproduction in any medium, provided you give appropriate credit to the original author(s) and the source, provide a link to the Creative Commons license, and indicate if changes were made.

\section{Literatuur}

1. Srinivasan R, Greenbaum DS. Chronic abdominal wall pain: a frequently overlooked problem. Practical approach to diagnosis and management. Am J Gastroenterol. 2002;97(4):824-30.

2. Boelens OB, Scheltinga MR, Houterman S, Roumen RM. Management of anterior cutaneous nerve entrapment syndrome in a cohort of 139 patients. Ann Surg. 2011;254(6):1054-8.

3. Maatman RC, Boelens OB, Scheltinga MRM, Roumen RMH. Chronic localized back pain due to entrapment of cutaneous branches of posterior rami of the thoracic nerves (POCNES): a case series on diagnosis and management. JPain Res. 2019;12:715-23.

4. Roumen RMH, Scheltinga MRM. Abdominale intercostale neuralgie: een vergeten oorzaak van buikpijn. Ned Tijdschr Geneeskd. 2006;150(35):1909-15.

5. Maatman RC, Papen-Botterhuis NE, Scheltinga MRM, Roumen RMH. Lateral cutaneous nerve entrapment syndrome (LACNES): a previously unrecognized cause of intractable flank pain. Scand J Pain. 2017;17:211-7.

6. Boelens OB, Maatman RC, Scheltinga MR, Laarhoven Kvan, Roumen RM. Chronic localized back pain due to posterior cutaneous nerve entrapment syndrome (POCNES): a new diagnosis. Pain Phys. 2017;20(3):E455-E8.

7. Seventer R van, Vos C, Meerding W, Gal M le, Bouhassira D, Huygen FJ. Linguistic validation of the DN4 for use in international studies. Eur J Pain. 2010;14(1):58-63.

8. Seventer R van, Vos C, Giezeman M, Meerding W-J, Arnould B, Regnault A, et al. Validation of the Dutch version of the DN4 diagnostic questionnaire for neuropathic pain. Pain Pract. 2013;13(5):390-8.

9. MolFMU, Jansen CH, Boelens OB, Stronks DL, Eerten Pvan, Huygen FJPM, et al. Adding steroids to lidocaine in a therapeutic injection regimen for patients with abdominal pain due to anterior cutaneous nerve entrapment syndrome (ACNES): a single blinded randomized clinical trial. Scand J Pain. 2018;18(3):505-12.

10. Mol FMU, Maatman RC, De Joode LEGH, Van Eerten P, Scheltinga MR, Roumen R. Characteristics of 1116 consecutive patients diagnosed with anterior cutaneous nerve entrapment syndrome (ACNES). Ann Surg. 2019; https:// doi.org/10.1097/SLA.0000000000003224.

11. Glissen BrownJR, Bernstein GR, FriedenbergFK, EhrlichAC. Chronic abdominal wall pain: an under-recognized diagnosis leading to unnecessary testing. J Clin Gastroenterol. 2016;50(10):828-35.

12. Farrar JT, Young JP Jr, LaMoreaux L, Werth JL, Poole RM. Clinical importance of changes in chronic pain intensity measured on an 11-point numerical pain rating scale. Pain. 2001;94(2):149-58.

13. Forouzanfar T, Weber WE, Kemler M, Kleef M van. What is a meaningful pain reduction in patients with complex regional pain syndrome type 1? Clin J Pain. 2003;19(5):281-5.

14. Maatman RC, Kuijk SMJ van, Steegers MAH, Boelens OBA, Lim TC, Scheltinga MRM, et al. A randomized controlled trial to evaluate the effect of pulsed radiofrequency as a treatment for anterior cutaneous nerve entrapment syndrome in comparison to anterior neurectomy. Pain Pract. 2019;19(7):751-61.

drs. Olaf. P.J. Vrooman, uroloog

dr. Michael R. van Balken, uroloog 